OPEN ACCESS

Edited by:

Ekrem Dere

Sorbonne Universités, France

Reviewed by:

Siv Vingill,

University of Oxford, United Kingdom

Terence Y. Pang,

The Florey Institute of Neuroscience and Mental Health, Australia

*Correspondence: Yvonne Bouter

Yvonne.bouter@

med.uni-goettingen.de

Received: 28 February 2019

Accepted: 02 May 2019

Published: 17 May 2019

Citation:

Wagner JM, Sichler ME,

Schleicher EM, Franke TN, Irwin C, Löw MJ, Beindorff N, Bouter $C$

Bayer TA and Bouter Y (2019)

Analysis of Motor Function

in the Tg4-42 Mouse Model

of Alzheimer's Disease.

Front. Behav. Neurosci. 13:107.

doi: 10.3389/fnbeh.2019.00107

\section{Analysis of Motor Function in the Tg4-42 Mouse Model of Alzheimer's Disease}

\author{
Jannek M. Wagner ${ }^{1}$, Marius E. Sichler ${ }^{1}$, Eva M. Schleicher ${ }^{1}$, Timon N. Franke ${ }^{1}$, \\ Caroline Irwin'1, Maximilian Johannes Löw ${ }^{1}$, Nicola Beindorff², Caroline Bouter ${ }^{3}$, \\ Thomas A. Bayer ${ }^{1}$ and Yvonne Bouter ${ }^{1 *}$
}

'Division of Molecular Psychiatry, Department of Psychiatry and Psychotherapy, University Medical Center Göttingen, Georg-August-University, Göttingen, Germany, ${ }^{2}$ Berlin Experimental Radionuclide Imaging Center, Charité - University Medicine Berlin, Berlin, Germany, ${ }^{3}$ Department of Nuclear Medicine, University Medical Center Göttingen,

Georg-August-University, Göttingen, Germany

Alzheimer's disease (AD) is a neurodegenerative disorder and the most common form of dementia. Hallmarks of $A D$ are memory impairments and cognitive deficits, but non-cognitive impairments, especially motor dysfunctions are also associated with the disease and may even precede classic clinical symptoms. With an aging society and increasing hospitalization of the elderly, motor deficits are of major interest to improve independent activities in daily living. Consistent with clinical findings, a variety of AD mouse models develop motor deficits as well. We investigated the motor function of 3- and 7-month-old Tg4-42 mice in comparison to wild-type controls and 5XFAD mice and discuss the results in context with several other AD mouse model. Our study shows impaired balance and motor coordination in aged Tg4-42 mice in the balance beam and rotarod test, while general locomotor activity and muscle strength is not impaired at 7 months. The cerebellum is a major player in the regulation and coordination of balance and locomotion through practice. Particularly, the rotarod test is able to detect cerebellar deficits. Furthermore, supposed cerebellar impairment was verified by ${ }^{18}$ F-FDG PET/MRI. Aged Tg4-42 mice showed reduced cerebellar glucose metabolism in the ${ }^{18} \mathrm{~F}$-FDG PET. Suggesting that, deficits in coordination and balance are most likely due to cerebellar impairment. In conclusion, Tg4-42 mice develop motor deficits before memory deficits, without confounding memory test. Thus, making the Tg4-42 mouse model a good model to study the effects on cognitive decline of therapies targeting motor impairments.

Keywords: motor function, cerebellum, Alzheimer, transgenic mice, behavior, FDG-PET

\section{INTRODUCTION}

Alzheimer's disease (AD) is a neurodegenerative disorder and the most common form of dementia. The main clinical symptoms of $\mathrm{AD}$ are memory impairments and cognitive deficits. However, non-cognitive impairments especially motor dysfunctions are also associated with the disease. The observed motor deficits range from impaired balance and gait changes to disturbed activity levels (Larson et al., 1992; O'Keeffe et al., 1996; Pettersson et al., 2002; Camicioli et al., 2006). 
In $\mathrm{AD}$ patients, motor impairments may even precede the clinical symptoms, providing a link between motor function and the development of AD (Buchman and Bennett, 2011).

Motor signs (MOSIs) decline with age and severity of the disease. The most affected MOSIs are speech, facial expression, rigidity, posture, gait, bradykinesia, and less frequently tremor (Scarmeas et al., 2004).

From mild to moderate $\mathrm{AD}$ the decline in motor abilities is stronger than from moderate to severe $\mathrm{AD}$ and associated with an increased risk of falls (Zidan et al., 2012). Slowing in fine motor dexterity seems to depend on the severity of the disease and is associated with functional decline in the active daily living (de Paula et al., 2016). In the 'Sydney Older Persons Study' a combination of cognitive decline and motor deficits was investigated over a 6-year period. Motor slowing and gait abnormalities resulted in poorer outcome of patients with dementia. Patients with decreased motor abilities were more likely to have severe cognitive impairments and even died earlier (Waite et al., 2005). Another study showed that gait abnormalities in aged patients without the diagnosis of dementia at baseline were related to lower cognitive performance and an increased incidence of mild cognitive impairment (MCI) or dementia (Beauchet et al., 2014). Wilson et al. (2000) showed a link between progression in parkinsonism (bradykinesia, gait disorder/postural reflex impairment, rigidity, tremor) and the progression of cognitive decline in $\mathrm{AD}$ patients. Furthermore, rigidity has been shown to be linked to death as well and to increased hospitalization in AD patients (Lopez et al., 1997).

Consistent with clinical findings, a variety of $\mathrm{AD}$ mouse models develop motor deficits (Kobayashi and Chen, 2005; Wirths and Bayer, 2008) (Table 1). There are several well established behavioral tests to assess motor function, coordination and balance in rodents such as the rotarod test, balance beam task, string suspension task, inverted grip strength task and the Open Field task for locomotor activity (Brooks and Dunnett, 2009; Deacon, 2013).

While the exact etiology of AD is still not fully understood, considerable evidence points to amyloid-beta peptides (A $\beta$ ) as a key player in the pathogenesis of $\mathrm{AD}$. According to the amyloid cascade hypothesis, $A \beta$-plaques seem to play a causative role in the pathogenesis of AD (Hardy and Higgins, 1992). More recent data claim that, truncated and modified $\mathrm{A} \beta$ variants play an important role next to full-length $A \beta$. Especially $\mathrm{N}$-truncated forms of $\mathrm{A} \beta$ enhance aggregation and neurotoxicity (Pike et al., 1995; Bayer and Wirths, 2014). Among the different species, $A \beta$ beginning with phenylalanine at position 4 is particularly abundant in the brain of $\mathrm{AD}$ patients (Masters et al., 1985; Portelius et al., 2010). The transgenic mouse model Tg4-42 expresses exclusively intraneuronal A $\beta 4-42$ without human amyloid precursor protein (APP) overexpression (Bouter et al., 2013). Intracellular $A \beta$ accumulation is accompanied by micro- and astrogliosis that is most abundant in the hippocampus of these mice. Tg4-42 mice develop severe synaptic impairments and neuron loss especially in the CA1 region of the hippocampus. Furthermore, Tg4-42 mice develop age-dependent behavior and memory deficits albeit without plaque formation (Bouter et al., 2013, 2019; Dietrich et al., 2013).
The aim of the current study was to extend previous findings on the Tg4-42 model by examining motoric abilities and compare these results with the widely used 5XFAD mouse model. We investigated mice at 3 months, with no known memory deficits in comparison with 7-month-old mice, which already present strong memory deficits. Furthermore, we discuss the results in the context of other, well-studied AD models, to facilitate model selection for further research on the causes of motor impairments related to $\mathrm{AD}$ and the development of possible therapies.

\section{MATERIALS AND METHODS}

\section{Transgenic Mice}

The generation of Tg4-42 mice has been described previously (Bouter et al., 2013). Briefly, Tg4-42 mice express human A $\beta 4-42$ fused to the murine thyrotropin releasing hormone signal peptide under the control of the neuronal Thy-1 promoter. Tg4-42 mice were generated and maintained on a C57Bl/6J genetic background. Only homozygous Tg4-42 mice were used in this study.

The double transgenic 5XFAD model (Jackson Laboratories, Bar Harbor, ME, United States) over-expresses the 695 amino acids isoform of the human amyloid precursor protein (APP695) carrying the Swedish, London, and Florida mutations under the control of the murine Thy-1 promoter. In addition, human presenilin-1 (PSEN-1) carrying the M146L/L286V mutations is also expressed under the control of the murine Thy-1 promoter in 5XFAD mice (Oakley et al., 2006). 5XFAD mice used in the current study were kept on a $\mathrm{C} 57 \mathrm{Bl} / 6 \mathrm{~J}$ genetic background (Jawhar et al., 2012). Wild-type littermates served as age-matched control animals. In the current study, only female mice were used.

All animals were handled according to the guidelines of the 'Society for Laboratory Animals Science' (GV-SOLAS) and the guidelines of the 'Federation of European Laboratory Animal Science Association' (FELASA). All experiments were approved by the 'Lower Saxony State Office for Consumer Protection and Food Safety' (LAVES).

Mice were kept on a $12 \mathrm{~h} / 12 \mathrm{~h}$ inverted light cycle and behavior experiments were performed during the dark phase. Mice were subjected to a battery of behavior tests at 3 and 7 months of age to assess possible motor deficits. Weight was monitored as part of a general physical assessment.

\section{Paw-Clasping Test}

The clasping test was used to test for functional impairments (Jawhar et al., 2012). Each mouse was suspended by their tail for $30 \mathrm{~s}$ to provoke a clasping phenotype. Healthy mice try to escape the grip by twisting their body and kicking their paws and therefore do not show any clasping phenotype. Clasping behavior was scored on a scale from zero to three: $0=$ no clasping behavior, 1 = fore paws clasping, 2 = one hind paw and fore paws clasping, 3 = clasping of all paws (Miller et al., 2008).

\section{String Suspension}

Grip strength and general motor coordination were analyzed using the string suspension task as described previously 
TABLE 1 | Motor function of different AD mouse models.




TABLE 1 | Continued

\begin{tabular}{|c|c|c|c|c|c|c|c|c|}
\hline Mouse model & References & Test age & Sex & Open Field & Rotarod & $\begin{array}{c}\text { Balance } \\
\text { beam } \\
\text { walk }\end{array}$ & $\begin{array}{c}\text { String } \\
\text { susp. task }\end{array}$ & $\begin{array}{l}\text { Grip } \\
\text { strength } \\
\text { tasks }\end{array}$ \\
\hline \multirow{9}{*}{$\begin{array}{l}\text { 3xTg } \\
\text { APP }_{\text {SweK670M/N671L, }} \\
\text { PS1M136V, MAPT }_{\text {P301L }} \\
\text { (Oddo et al., 2003) }\end{array}$} & \multirow[t]{5}{*}{ Oore et al., 2013} & 1) $2 \mathrm{~m}$ & 우 & - & $\uparrow$ & - & - & - \\
\hline & & 2) $6 \mathrm{~m}$ & @० & - & $\uparrow$ & - & - & - \\
\hline & & 3) $9 \mathrm{~m}$ & 이 & - & $\uparrow$ & - & - & - \\
\hline & & 4) $12 \mathrm{~m}$ & 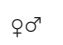 & - & $\uparrow$ & - & - & - \\
\hline & & 5) $15 \mathrm{~m}$ &  & - & $\uparrow$ & - & - & - \\
\hline & Stover et al., 2015 & 1) $6 \mathrm{~m}$ & qo & - & $\uparrow$ & ns & ns & $\downarrow$ \\
\hline & Garvock-de Montbrun et al., 2019 & 1) $16 \mathrm{~m}$ & 욱 & - & $\uparrow$ & ns & ns & ns \\
\hline & Filali et al., 2012 & 1) $12-14 \mathrm{~m}$ & 인 & $\downarrow$ & $\downarrow$ & - & - & - \\
\hline & Gulinello et al., 2009 & 1) $15-18 \mathrm{~m}$ & क्ष & $\downarrow$ & - & ns & - & - \\
\hline \multirow{8}{*}{$\begin{array}{l}\text { TBA } 42 \\
\text { A } \beta_{p E 3-42} \\
\text { (Wittnam et al., 2012) }\end{array}$} & \multirow[t]{3}{*}{ Meissner et al., 2014} & 1) $3 \mathrm{~m}$ & १๐ & - & - & ns & $\downarrow$ & ns \\
\hline & & 2) $6 \mathrm{~m}$ & १० & - & - & $\downarrow$ & $\downarrow$ & $\downarrow$ \\
\hline & & 3) $12 \mathrm{~m}$ & qo & - & - & $\downarrow$ & $\downarrow$ & $\downarrow$ \\
\hline & \multirow[t]{3}{*}{ Wittnam et al., 2012} & 1) $3 \mathrm{~m}$ & q & - & - & ns & - & - \\
\hline & & 2) $6 \mathrm{~m}$ & q & - & - & ns & - & - \\
\hline & & 3) $12 \mathrm{~m}$ & q & - & - & $\downarrow$ & - & - \\
\hline & \multirow[t]{2}{*}{ Lopez-Noguerola et al., 2018} & 1) $3-4 \mathrm{~m}$ & ণo & - & - & ns & ns & ns \\
\hline & & 2) 5-6 m & १o & - & - & $\downarrow$ & $\downarrow$ & $\downarrow$ \\
\hline \multirow{4}{*}{$\begin{array}{l}\text { Tg4-42 } \\
\text { A } \beta_{4-42} \\
\text { (Bouter et al., 2013) }\end{array}$} & \multirow[t]{2}{*}{ Lopez-Noguerola et al., 2018} & 1) $3-4 \mathrm{~m}$ & qox & - & - & ns & ns & ns \\
\hline & & 2) $5-6 \mathrm{~m}$ & १๐ & - & - & ns & ns & ns \\
\hline & \multirow[t]{2}{*}{ Current study } & 1) $3 \mathrm{~m}$ & q & ns & $\downarrow$ & ns & ns & ns \\
\hline & & 2) $7 \mathrm{~m}$ &  & ns & $\downarrow$ & $\downarrow$ & ns & ns \\
\hline
\end{tabular}

w, weeks; m, months; ns, not significant.

(Jawhar et al., 2012). In brief, mice were permitted to grasp a cotton string with their fore paws and were then released. Their ability to climb across the string was assessed using a 0 to 5 rating score: $0=$ falls of string; $1=$ hangs onto string by fore- or hind paws; 2 = hangs onto string by fore- or hind paws and attempts to climb onto string; $3=$ hangs onto string by all four paws but no lateral movement; 4 = hangs onto string using all four paws and tail and moves laterally; 5 = escapes to the edge of string and touches wooden support beam (Moran et al., 1995). Each animal performed three 60-s trials throughout 1 day with a minimum of $30 \mathrm{~min}$ between the trials. The average score of all three trials was taken for each mouse.

\section{Balance Beam}

Fine motor coordination and balance of mice were assessed using the balance beam test as previously described (Jawhar et al., 2012). The test essentially examines the ability of a mouse to remain upright and to walk on the relatively narrow and elevated beam to one of the platforms. During a single day of testing each mouse was given three 60-s trials with a minimum of $10 \mathrm{~min}$ between the trials. The average time of all three trials was taken as the score for each mouse. A test trial was given to familiarize the mouse with the beam. For each trial, the mouse was placed in the center of the beam facing one of the platforms and then released. The latency to fall from the beam was recorded. If a mouse escaped to one of the platforms or remained on the beam for the entire trial, the maximum time of $60 \mathrm{~s}$ was given.

\section{Inverted Grip Task}

Neuromuscular abilities and muscle strength were tested with the inverted grip test as previously described (Wirths et al., 2008). Mice were placed on a metal grid and turned upside down $30 \mathrm{~cm}$ elevated above a padded surface. Latency to fall within $60 \mathrm{~s}$ was measured in one single trial.

\section{Rotarod}

Motor performance and motor learning were tested using the rotarod (TSE Systems, Germany). Testing consists of four trials per day for two consecutive days with intertrial intervals of 10-15 min. Each mouse was placed on the rod, which accelerated from 4 to $40 \mathrm{rpm}$. over the trial time of $300 \mathrm{~s}$. Trials were terminated when animals fell off or the maximum time was reached. Up to five mice were tested simultaneously, separated by black plastic walls. Mice were taken out of the apparatus when the last mouse fell. Latency to fall served as an indicator of motor coordination.

\section{${ }^{18}$ F-FDG PET/MRI}

${ }^{18}$ F-fluoro-deoxy-glucose positron emission tomography/ magnetic resonance image $\left({ }^{18} \mathrm{~F}-\mathrm{FDG}\right.$-PET/MRI) acquisition and analysis were used to evaluate brain glucose metabolism in the cerebellum of 7-month-old Tg4-42 mice and 5XFAD mice. Female Tg4-42 $(n=5)$, 5XFAD $(n=3)$ and wild-type C57Bl/6J $(n=5)$ control mice were fasted overnight and blood glucose levels were measured. As previously described 9-21 MBq (mean $15.76 \mathrm{MBq}$ ) of ${ }^{18}$ F-FDG were administered 
intravenously into a tail vein with a maximum volume of $200 \mu \mathrm{l}$ (Bouter et al., 2019). Mice were anesthetized with isoflurane supplemented with oxygen during the scans and were awake during the uptake period. After an uptake period of $45 \mathrm{~min}$, PET imaging was performed on a small animal 1 Tesla nanoScan PET/MRI (Mediso, Hungary). During the scan mice were placed on a $37^{\circ} \mathrm{C}$ heated bed. Respiration rate was monitored constantly during the scans. PET scans were performed for $20 \mathrm{~min}$. MRI-based attenuation correction was conducted (matrix $144 \times 144 \times 163$ with a voxel size of $0.5 \times 0.5 \times 0.6 \mathrm{~mm}^{3}$, TR: $15 \mathrm{~ms}$, TE $2.032 \mathrm{~ms}$ and a flip angle of $25^{\circ}$ ) and the PET images were reconstructed with the following parameters: matrix $136 \times 131 \times 315$ with a voxel size of $0.23 \times 0.3 \times 0.3 \mathrm{~mm}^{3}$. Image analysis was performed using PMOD v3.9 (PMOD Technologies, Switzerland). A predefined mouse brain atlas template was used to analyze different brain areas including the cerebellum $(\mathrm{Cb})$. Corresponding PET images were matched to the MRI and statistics within the cerebellum volume of interest (VOI) in $\mathrm{kBq} / \mathrm{cc}$ were generated. Standardized uptake value (SUV) was calculated [SUV = tissue activity concentration average $(\mathrm{KBq} / \mathrm{cc}) \times$ body/weight $(\mathrm{g}) /$ injected dose $(\mathrm{kBq})$ ] for semi-quantitative analysis and SUV values were corrected for blood glucose levels [SUVGlc $=$ SUV $\times$ blood glucose level (mg/dl)].

\section{Statistical Analysis}

Differences between groups were tested with one-way analysis of variance (ANOVA) or two-way ANOVA followed by analysis of Bonferroni multiple comparison indicated. All data are given as mean \pm standard error of the mean (SEM). Significance levels are given as follows: ${ }^{* * *} p<0.001 ;{ }^{* *} p<0.01{ }^{*} p<0.05$. GraphPad Prism version 6.07 for Windows (GraphPad Software, San Diego, CA, United States) was used for all calculations.

\section{RESULTS}

\section{Normal Body Weight of Tg4-42 and 5XFAD Mice}

The body weight of all mice was taken at 3 and 7 months of age. Tg4-42 and 5XFAD mice demonstrated no altered body weight compared to wild-type mice at the tested time points [Figure 1A, two-way ANOVA, genotype: $F(2,66)=3.744$, $p=0.0688]$. Statistically significant was the gain of weight of Tg4-42 and 5XFAD mice, but although wild-type mice gained some weight as well, this effect was not statistically significant [Figure 1A, two-way ANOVA, age: $F(1,66)=18.55, p<0.0001$, post hoc analysis Tg4-42: $p<0.01,5 \mathrm{XFAD}: p<0.05]$.

\section{Clasping Phenotype in 7-Month-Old 5XFAD Mice}

At 3 months none of the tested animals showed any clasping phenotype. However, 5XFAD mice develop an age-dependent clasping phenotype [Figure 1B, two-way ANOVA, age: $F(1,66)=10.61, p=0.0019$; genotype: $F(2,66)=12.12, p<0.001]$.
Tg4-42 mice did not show a clasping behavior at 7 months and they tried to escape the grip by twisting their body and kicking their paws similar to wild-type animals.

\section{Impaired Sensorimotor Function in Tg4-42 Mice}

Fine motor coordination and balance of mice can be assessed by the balance beam task (Hau and Schapiro, 2002; Luong et al., 2011). At the age of 3 months none of the tested animals showed impairments in the balance beam task. However, 7-month-old Tg4-42 mice spent significantly less time on the beam compared to same-aged wild-type animals [Figure 2A, two-way ANOVA, genotype: $F(2,66)=3.702 ; p<0.05]$. Tg4-42 mice showed an age-dependent decline in balance and motor coordination [Figure 2A, two-way ANOVA, Tg4-42 age: $F(1,66)=5.904$, $p=0.0178$; post hoc analysis Tg4-42: $p<0.05]$. In contrast, aged $5 \mathrm{XFAD}$ mice performed similar to wild-type controls.

\section{Unaltered Grip Strength in 5XFAD and Tg4-42 Mice}

The string suspension task evaluates motor coordination, grip and muscle strength of mice (Hullmann et al., 2017), whereas the inverted grip task assesses muscle strength (Deacon, 2013). Neither 5XFAD, nor Tg4-42 mice showed a lower grip strength in any of these tests compared to wild-type control mice [Figures 2B,C, two-way ANOVA, string suspension genotype: $F(2,66)=0.9058, p=0.4092$, age: $F(1,66)=0.450, p=0.5047$; inverted grip genotype: $F(1,66)=2.435, p=0.1234$, age: $F(1,66)=2.435, p=0.1234]$.

\section{Decreased Locomotor Activity of 5XFAD, but Not Tg4-42 Mice in the Open Field Task}

To measure general locomotor activity, mice were tested in an Open Field task (Seibenhener and Wooten, 2015). Tg442 mice traveled the same distance as wild-type controls, showing no impaired locomotor activity at any tested age. On the other hand, 5XFAD mice traveled less, showing an age-dependent decreased in locomotor activity [Figure 2D, two-way ANOVA, age: $F(1,71)=22.33, p<0.001$; genotype: $F(2,71)=3.706, p=0.0294]$.

\section{Impaired Motor Learning Skills in Tg4-42 Mice}

The rotarod task assesses motor skill learning abilities and coordination (Buitrago et al., 2004; Deacon, 2013). Performance of 5XFAD mice did not differ from wild-type controls at 3 or 7 months of age. While young Tg4-42, 5XFAD and WT mice showed an overall improved motor learning over the training trials [Figure 2E, two-way ANOVA, trials: $F(7,210)=20.18$, $p<0.0001]$, Tg4-42 displayed a shorter latency to fall on the last trial compared to same-aged wild-type animals [Figure $2 \mathbf{E}$, two-way ANOVA, genotype: $F(2,30)=1.114, p=0.3413$; post hoc analysis Tg4-42 trial 8: $p<0.05]$. At 7 months of age Tg4-42 mice showed decreased motor learning and performed significantly 



FIGURE 1 | General physical assessment of Tg4-42 and 5XFAD mice. (A) 3- and 7-month-old Tg4-42 and 5XFAD mice displayed normal body weight compared to aged-matched wild-type mice. (B) Wild-type and Tg4-42 mice showed no clasping phenotype during the tail suspension task regardless of age. 5XFAD mice showed a clasping phenotype at 7 months of age. Two-way repeated measures ANOVA, ${ }^{*} p<0.05,{ }^{* *} p<0.01,{ }^{* * *} p<0.001 ; n=12$ per group; data presented as mean \pm SEM; WT, wild-type; $m$, months.

worse than wild-type and 5XFAD animals [Figure 2F, two-way ANOVA, genotype: $F(2,41)=33.00, p<0.0001]$.

\section{Decreased Metabolic Activity in the Cerebellum of Aged Tg4-42 Mice}

${ }^{18}$ F-FDG-PET/MRI was used to determine cerebellar glucose metabolism. Quantitative analysis of FDG-uptake was performed using a mouse brain atlas and blood glucose corrected SUV values (SUVglc) were measured within a predefined cerebellum VOI (Figure 3B). Seven-month-old Tg4-42 and 5XFAD mice showed significantly decreased ${ }^{18} \mathrm{~F}-\mathrm{FDG}$ uptake in the cerebellum compared to wild-type mice [Figures 3A,C,D, one-way-ANOVA, $F(2,11)=2.007, p=0.0018$; post hoc analysis WT vs. Tg4-42: $p<0.01$; WT vs. 5XFAD: $p<0.05]$.

\section{DISCUSSION}

Impairments of motor abilities are an important phenotype in the progression of $\mathrm{AD}$. Several studies show a decline in motor function throughout the progression of the disease in patients (Zidan et al., 2012; Beauchet et al., 2014; de Paula et al., 2016). Furthermore, motor impairments can be useful in the prediction of the onset as well as the outcome of AD (Waite et al., 2005). In an aging society, maintaining motor performance in $\mathrm{AD}$ patients should be of major interest to help to facilitate independence in daily living and activity (Yan and Zhou, 2009). Assessing motor deficits through physical exercise in preclinical stages of AD could delay or decline the development of $\mathrm{AD}$ as shown previously (Larson et al., 2006). Thus, motor deficits are an important symptom to study in $\mathrm{AD}$.

Similar to AD patients, most mouse models mimicking $\mathrm{AD}$ show motor impairments as the disease progresses. This study compared motor behavior of young and aged Tg4-42 mice with their age-matched wild-type controls and compared the results with other $\mathrm{AD}$ mouse models. Motoric performance of $\mathrm{AD}$ mice ranges from unaltered and impaired to improved motor performance. There are several tests to assess motor abilities in mice, but protocols and experimental apparatus differ highly between laboratories, complicating the comparison of results. These differences in behavior tests should always be taken into consideration (Table 1).

Weight can severely influence the outcome of behavior studies. Therefore, the animal's weight should always be taken into consideration especially when analyzing motor performance in mice. Previous studies showed that body weight significantly correlates with the performance of mice in the rotarod task, a test widely used to assess grip strength, motor coordination and balance (Brown and Wong, 2007; Shiotsuki et al., 2010). The weight of young and aged Tg4-42 mice was comparable to same-aged wild-type and 5XFAD mice in this study. In contrast, weight loss has previously been observed in several other $\mathrm{AD}$ mouse models. A reduction in the gain of body weight has been described especially in mouse models overexpressing APP (Lalonde et al., 2005a; Pugh et al., 2007; Alexandru et al., 2011). For example, 9-month-old 5XFAD mice showed a significantly reduced body weight in comparison to their wild-type littermates (Jawhar et al., 2012). Interestingly, epidemiologic studies showed that weight loss is often associated with $\mathrm{AD}$ and can be observed in all stages of the disease (Gillette-Guyonnet et al., 2000; Guérin et al., 2005; Cova et al., 2016). Weight loss in $\mathrm{AD}$ patients often correlates with a general health decline and is suggested as a clinical predictor of mortality (White et al., 1998). In mice, weight variances can also indicate poor health and a lack of body weight gain might contribute to predicting mortality.

In contrast to 5XFAD mice, Tg4-42 mice did not show a limb clasping phenotype. Aged 5XFAD mice exhibited motor abnormalities and abnormal extension reflexes by retracting their hind- and fore paws simultaneously when suspended by the tail. An abnormal clasping pattern has been observed in several mouse models including mice transgenic for human four-repeat tau and mutant human APP (Probst et al., 2000; Lalonde et al., 2012), as well as APP/PS1KI and 5XFAD mice. Interestingly, all of these mice showed signs of axonopathy (Tesseur et al., 2000; Wirths et al., 2007; Jawhar et al., 2012). But surprisingly, the number of motor neurons of 6-month-old 5XFAD mice in the cervical spinal cord was similar to wild-type littermates (Chu et al., 2017). Both 
A


E



B

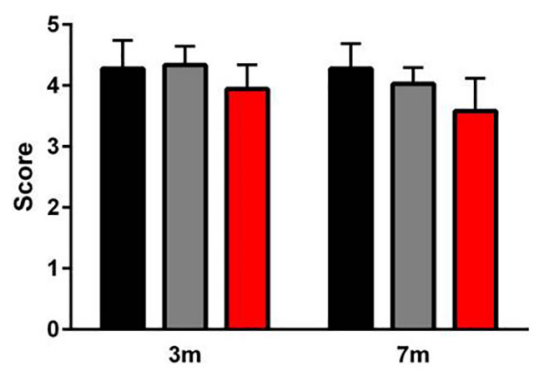

D

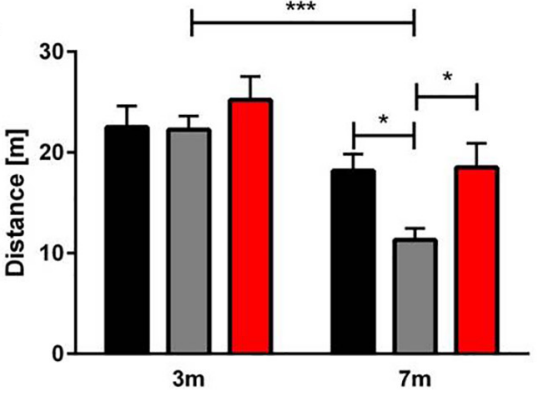

F



FIGURE 2 | Motor deficits in aged Tg4-42 mice. (A) Tg4-42 mice showed age-dependent motor deficits in the balance beam. 5XFAD mice displayed no deficits in the balance beam. Tg4-42 and 5XFAD mice performed similar to same-aged wild-type control mice in the (B) string suspension task and (C) inverted grip task. (D) 5XFAD mice displayed an age-dependent decreased distance traveled in the Open Field task. Seven-month-old 5XFAD mice traveled significantly less than same-aged Tg4-42 and wild-type mice. (E) Young Tg4-42 and 5XFAD mice showed a similar latency to fall on the accelerating rotarod on trials 1-7. On the last trial of the test Tg4-42 mice performed worse than same-aged wild-type mice. (F) Aged Tg4-42 mice showed a decreased performance on the accelerating rotarod compared to same-aged wild-type and 5XFAD mice. Two-way repeated measures ANOVA, vs. 5XFAD \#\#\# $p<0.001 ;$ vs. WT $* * * p<0.001 ; * p<0.05 ; n=9-15$ per group, data presented as mean \pm SEM; WT, wild-type; $m$, month.

Tg4-42 and 5XFAD mice show intracellular $\mathrm{A} \beta$ accumulation in the spinal cord, but only 5XFAD show signs of axon swelling and axonopathy (Jawhar et al., 2012; Lopez-Noguerola et al., 2018).

The Open Field locomotion test can be used to examine motor function by measuring spontaneous activity in an open arena (Lee et al., 2009). The Open Field task is an easy task to perform and measures general locomotor activity in mice (Seibenhener and Wooten, 2015). Our results show that Tg4-42 mice did not have alterations in locomotor activity. In contrast, 5XFAD mice showed lower activity levels consistent with previous studies (Sawmiller et al., 2017). Surprisingly, O'Leary et al. (2018a) found increased locomotor activity in 6- to 7-month-old female 5XFAD mice. This variation is likely due to different experimental protocols. However, in older 5XFAD mice the data is consistently showing reduced locomotor activity (Schneider et al., 2014; Griñán-Ferré et al., 2016;
O'Leary et al., 2018a,b) (Table 1). Altered locomotor activities need to be taken into consideration when interpreting results of behavioral tests such as anxiety-related or memory-related tests (Crawley and Bailey, 2008; Brooks et al., 2012; Deacon, 2013). Nevertheless, Tg4-42 mice did not show any impairments in the Open Field that could possibly influence anxiety- and memory-related behavior. In line with these findings, general motor abilities of Tg4-42 mice have been shown to be intact in the Morris water maze as swimming speed did not differ from wild-type animals (Bouter et al., 2013, 2014, 2019; Antonios et al., 2015).

Generally speaking, APP single-transgenic mice seem to show increased locomotor activity at young ages (King and Arendash, 2002; Harris et al., 2010), whereas mouse models with multiple mutations develop impairments at an older age (Gulinello et al., 2009; Filali et al., 2012; O’Leary et al., 2018a). Similar to Tg4-42 

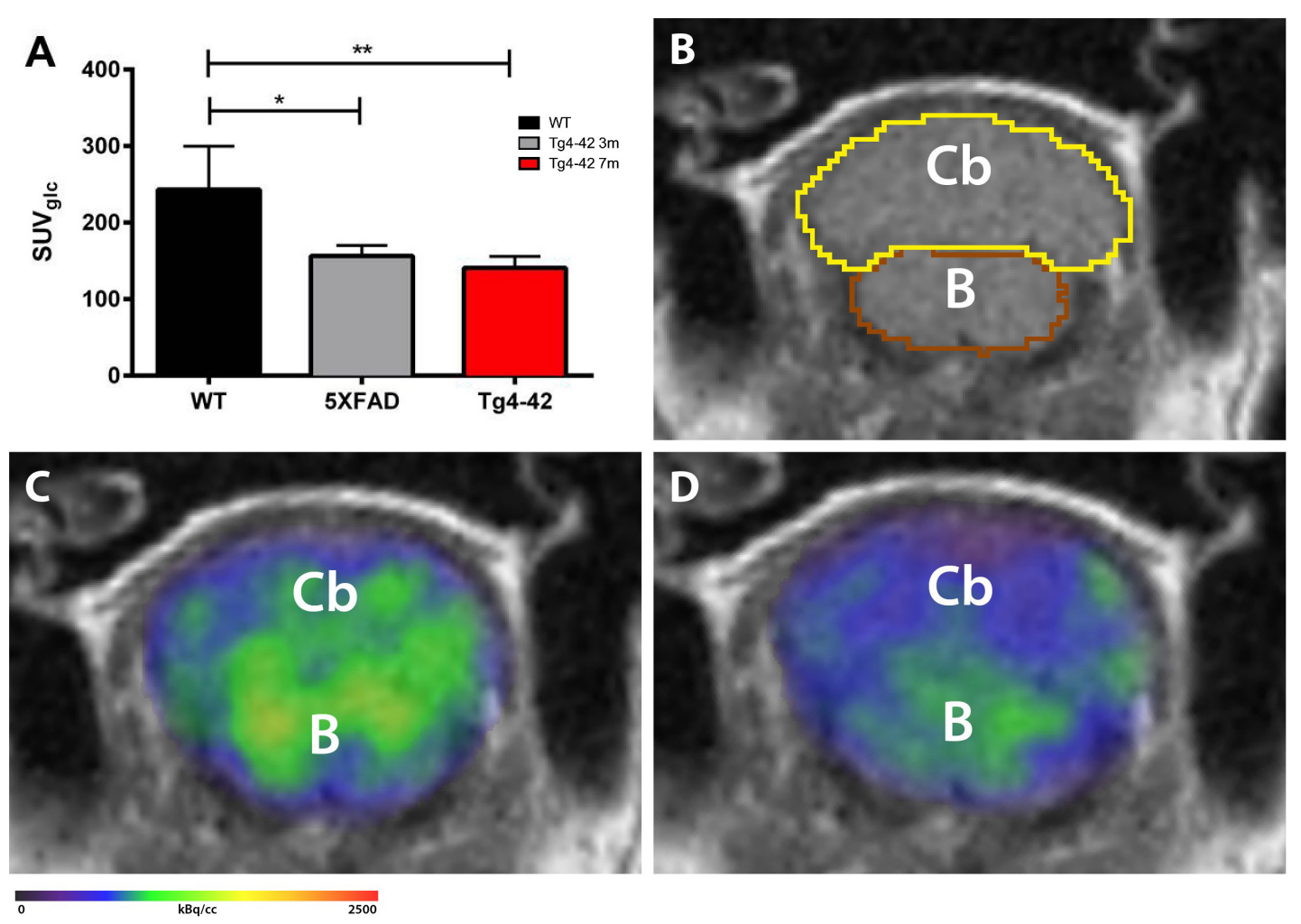

FIGURE 3 ${ }^{18} \mathrm{~F}$-FDG-PET shows decreased metabolic activity in the cerebellum of 7-month-old Tg4-42 and 5XFAD mice. (A) Quantification of ${ }^{18} \mathrm{~F}-\mathrm{FDG}$ uptake in the cerebellum. ${ }^{18} \mathrm{~F}$-FDG-uptake in the cerebellum was significantly reduced in aged Tg4-42 and 5XFAD mice compared to wild-type. (B) Magnetic resonance image (MRI; coronal view) with volumes of interest (VOIs) of the mouse brain atlas MRIs of each mouse. (C) Fused ${ }^{18} \mathrm{~F}$-FDG-PET/MRI of a wild-type mouse in coronal view. (D) Fused ${ }^{18} \mathrm{~F}$-FDG-PET/MRI of a 7 -month-old Tg4-42 mouse in coronal view with distinctly lower FDG uptake compared to the wild-type mouse. One-way-ANOVA; ${ }^{* *} p<0.01 ;{ }^{*} p<0.05 ; \mathrm{WT}$, wild-type; $\mathrm{m}$, months; Cb, cerebellum; B, brainstem.

mice, double-transgenic mice carrying single APP and PS1 mutation are less likely to have locomotor activity impairments (Lalonde et al., 2004; Sadowski et al., 2004; Webster et al., 2013) (Table 1).

It has to be mentioned that the Open Field task is one of the tests with relatively high variability in experimental procedures (Walsh and Cummins, 1976). The material and the size of the arena, as well as the testing time, differ immensely between the protocols used in analyzing different $\mathrm{AD}$ models. For example, some mice were granted time to adapt to the apparatus (van Dam et al., 2003) and others not (Lalonde et al., 2005a; Harris et al., 2010; Jawhar et al., 2012). The amount of time tested ranged from 5 min (Arendash et al., 2001; Jawhar et al., 2012; O'Leary et al., 2018a) to $30 \mathrm{~min}$ (Dineley et al., 2002; Webster et al., 2013). In addition, most mice were placed into the center of the box (King and Arendash, 2002; Jawhar et al., 2012), whereas others started in the corners (van Dam et al., 2003; O'Leary et al., 2018a). While most studies use only a single trial, other groups tested the same mouse multiple times and therefore assessing habituation rather than spontaneous locomotor activity alone (Dai et al., 1995; Lalonde et al., 2005b). Furthermore, the experimental apparatus used for the Open Field often differs in size, material, form or transparency between laboratories (King and Arendash, 2002;
Gulinello et al., 2009; Filali et al., 2012; Jawhar et al., 2012). These varieties need to be taken into consideration when comparing different $\mathrm{AD}$ mouse lines.

Several studies suggested a link between muscle strength and cognitive decline in AD patients (Boyle et al., 2009). In mice, the string suspension and grip strength test can be used to measure muscle strength (Deacon, 2013). We could show that 7-month-old Tg4-42 and 5XFAD mice did not present any impairments in muscle strength in the string suspension or grip strength tasks, consistent with previous findings for 5XFAD mice (Jawhar et al., 2012; Bhattacharya et al., 2014). However, previous studies showed a loss of muscle strength in both tests beginning at the age of 9 months (Jawhar et al., 2012). In contrast, O'Leary et al. (2018a) could show deficits already beginning from 6 to 7 months of age in 5XFAD mice. Generally speaking, a decline in muscle strength seems to be more frequent in aged $\mathrm{AD}$ mice (Table 1). Tg4-42 mice display severe memory deficits at 7 months of age and therefore mice were not tested for muscle strength at older ages, which should be investigated in upcoming studies to compare strength with other AD mouse models. The pyroglutamate A $33-42$ expressing mouse model TBA42 showed muscle strength deficits starting with 6 months, while muscle strength declined in Tg2576 not before 14 months, preceding memory deficits 
in both models (King and Arendash, 2002; Meissner et al., 2014) (Table 1). Interestingly, homozygous TBA42 had such severe motor deficits, that they had to be sacrificed at the age of 2 months (Lopez-Noguerola et al., 2018). APP+PS1 mice did not show signs of strength decline before 15 to 17 months of age (Holcomb et al., 1999; Arendash et al., 2001). APP+PS1 mice develop memory deficits at younger ages, similar to 5XFAD mice. Noteworthy, female and male $3 \times$ Tg mice show memory impairments before the onset of motor deficits with 16 months of age (Garvock-de Montbrun et al., 2019), similar to Tg4-42 mice (Table 1), but memory deficits do not progress through age in 3xTg mice (Stevens and Brown, 2015). These inconsistent findings with regard to onset of memory and motor deficits should be considered when choosing a suitable mouse model for research, depending on the symptom of interest.

Motor coordination is an important aspect of $\mathrm{AD}$ since bradykinesia and gait disturbances are part of $\mathrm{AD}$ motor impairments (Scarmeas et al., 2004), correlating with a poorer outcome of patients (Waite et al., 2005).

The rotarod and balance beam test are mainly used to test motor coordination and balance in mice. Additionally, the rotarod test assesses motor learning (Hamm et al., 1994; Le Marec and Lalonde, 1997; Luong et al., 2011; Deacon, 2013).

The cerebellum as a major player of motor control is important for regulation of balance and locomotion through practice (Morton and Bastian, 2004). Especially the rotarod task is able to detect motor disturbances through cerebellar dysfunction (Shiotsuki et al., 2010).

We could show deficits in the balance beam task of aged Tg4-42 mice. In context with Lopez-Noguerola et al. (2018) who tested younger Tg4-42 mice at the age of 5 months, an age dependent decline in balance and coordination could be observed. These findings suggest an onset of this deficit in the Tg4-42 mouse model for AD at the age of 6 to 7 months.

Deterioration in the rotarod test was already observed in young Tg4-42 mice and aggravated with age. Early deficits in the rotarod have been described in male APP23 mice (van Dam et al., 2003). In contrary Tg2567 mice did not show any impairment in the rotarod (Dineley et al., 2002; King and Arendash, 2002), but the balance beam test was able to detect deficits (King and Arendash, 2002). APP/PS1 KI mice did not show any motor deterioration and were comparable to controls at even older ages (Webster et al., 2013). Strikingly, male and female 3xTg mice performed better in rotarod task than controls up to the age of 16 months (Oore et al., 2013; Stover et al., 2015; Garvock-de Montbrun et al., 2019) (Table 1), but performance declined with age (Garvock-de Montbrun et al., 2019). Only Filali et al. (2012) who tested only female $3 x \mathrm{Tg}$ mice showed reduced performance in the rotarod, possibly due to protocol differences. Stover et al. (2015) suggests that tau P301L might be responsible for enhanced motor performance. Whereas other researchers found increased motor performance to be paradoxical (Filali et al., 2012), since other tau mouse models do present motor impairments in the rotarod test (Scattoni et al., 2010; Xu et al., 2010). Thus, suggesting no direct correlation between the transgene and severity of motor deficits.

Since Tg4-42 mice did not have altered muscle strength, we presumed that impairments in the balance beam task and rotarod was rather due to learning and balance, coordination impairments than muscle function. In previous studies we could show a severe learning deficit in the Morris water maze, beginning from the age of 5 months in Tg4-42 mice (Antonios et al., 2015). Interestingly, despite the massive impairments in the rotarod, the ability to swim in the Morris water maze was not altered in same-aged Tg4-42 mice (Bouter et al., 2013, 2014; Antonios et al., 2015).

The cerebellum is the center of motor function and contributes to motor learning by determining how to perform correct and accurate movements. It has been shown that cerebellar damage leads to disturbance in movements and body support (Porras-García et al., 2013) and cerebellar atrophy is characteristic for sporadic AD (Jacobs et al., 2018). Kuwabara et al. (2014) could detect relatively high levels of A $\beta 1-42$ in cerebellar lysates and impairments in the rotarod test in 3-month-old APP/PS1 mice, but no impairments in the balance beam test.

Subsequently, we analyzed the cerebellum of Tg4-42 mice via ${ }^{18}$ F-FDG-PET to detect possible synaptic dysfunctions. ${ }^{18} \mathrm{~F}$ FDG-PET, as a functional biomarker for synaptic dysfunction, confirmed findings of the behavioral tests showing reduced glucose metabolism in the cerebellum of aged Tg4-42 mice. Findings are in line with several earlier ${ }^{18}$ F-FDG-PET studies showing cerebellar hypo metabolism in different transgenic mouse models of AD (Platt et al., 2011; Macdonald et al., 2014; Deleye et al., 2016; Takkinen et al., 2017; Waldron et al., 2017; Bouter et al., 2019). But furthermore, intraneuronal $\mathrm{A} \beta$ accumulation in the spinal cord of $\mathrm{Tg} 4-42$ mice have been described previously (Lopez-Noguerola et al., 2018) and may contribute to motor deficits. But since strength was not yet affected in 7-month-old Tg4-42 mice we focused on the processing and coordination of motor function by in vivo imaging of the cerebellum.

Interestingly, a study by Macdonald et al. (2014) using ${ }^{18}$ F-FDG-PET in 2-, 5-, and 12-month-old 5XFAD mice showed decreased FDG-uptake in the cerebellum of 12-month-old 5XFAD mice while 2- and 5-month-old animals did not show significant differences to wild-type mice. In line with these findings, female 7-month-old 5XFAD performed as wild-type mice on the rotarod, while older mice display strong impairments (O'Leary et al., 2018a) (Table 1). However, 5XFAD mice showed decreased FDG-uptake as early as 7 months of age in our study. This seems to be an indicator of early cerebellar changes, even before motor impairments occur, as glucose metabolism is known to be an early marker of neuronal dysfunction.

Mouse models allow to investigate motor abilities and are suitable tools to analyze different aspects of $\mathrm{AD}$ pathologies and the effectiveness of possible therapies.

Tg4-42 displays an AD mouse model with intact general motor activity and strength, but age-dependent 
motor impairments in motor coordination and balance present at the age of 7 months, most likely due to impaired cerebellar activity.

\section{DATA AVAILABILITY}

The datasets generated for this study are available on request to the corresponding author.

\section{ETHICS STATEMENT}

All animals were handled according to the guidelines of the "Society for Laboratory Animals Science" (GV-SOLAS) and the guidelines of the "Federation of European Laboratory Animal Science Association" (FELASA). All experiments were approved by the "Lower Saxony State Office for Consumer Protection and Food Safety" (LAVES).

\section{AUTHOR CONTRIBUTIONS}

JW performed the experiments, analyzed the data, and wrote the manuscript. MS performed the experiments and

\section{REFERENCES}

Alexandru, A., Jagla, W., Graubner, S., Becker, A., Bäuscher, C., Kohlmann, S., et al. (2011). Selective hippocampal neurodegeneration in transgenic mice expressing small amounts of truncated $A \beta$ is induced by pyroglutamate- $A \beta$ formation. J. Neurosci. 31, 12790-12801. doi: 10.1523/JNeurosci.1794-11.2011

Antonios, G., Borgers, H., Richard, B. C., Brauß, A., Meißner, J., Weggen, S., et al. (2015). Alzheimer therapy with an antibody against N-terminal Abeta 4-X and pyroglutamate Abeta 3-X. Sci. Rep. 5:17338. doi: 10.1038/srep1 7338

Arendash, G. W., King, D. L., Gordon, M. N., Morgan, D., Hatcher, J. M., Hope, C. E., et al. (2001). Progressive, age-related behavioral impairments in transgenic mice carrying both mutant amyloid precursor protein and presenilin-1 transgenes. Brain Res. 891, 42-53. doi: 10.1016/S0006-8993(00) 03186-3

Bayer, T. A., and Wirths, O. (2014). Focusing the amyloid cascade hypothesis on $\mathrm{N}$-truncated Abeta peptides as drug targets against Alzheimer's disease. Acta Neuropathol. 127, 787-801. doi: 10.1007/s00401-014-1287-x

Beauchet, O., Allali, G., Montero-Odasso, M., Sejdić, E., Fantino, B., and Annweiler, C. (2014). Motor phenotype of decline in cognitive performance among community-dwellers without dementia: population-based study and metaanalysis. PLoS One 9:e99318. doi: 10.1371/journal.pone.0099318

Bhattacharya, S., Haertel, C., Maelicke, A., and Montag, D. (2014). Galantamine slows down plaque formation and behavioral decline in the 5XFAD mouse model of Alzheimer's disease. PLoS One 9:e89454. doi: 10.1371/journal.pone. 0089454

Bouter, C., Henniges, P., Franke, T. N., Irwin, C., Sahlmann, C. O., Sichler, M. E., et al. (2019). 18F-FDG-PET detects drastic changes in brain metabolism in the Tg4-42 model of Alzheimer's disease. Front. Aging Neurosci. 10:425. doi: 10.3389/fnagi.2018.00425

Bouter, Y., Dietrich, K., Wittnam, J., Pillot, T., Papot-Couturier, S., Lefebvre, T., et al. (2013). Tg4-42: a new mouse model of Alzheimer's disease-Ntruncated amyloid $\beta$ (A $\beta$ ) 4-42 induces severe neuron loss and behavioral deficits. Alzheimers Dement. 9, 498-499. doi: 10.1016/j.jalz.2013.05.1031

Bouter, Y., Kacprowski, T., Weissmann, R., Dietrich, K., Borgers, H., BrauÃź, A., et al. (2014). Deciphering the molecular profile of plaques, memory decline and analyzed the data. ES, ML, TF, NB, and CI performed the experiments. $\mathrm{CB}$ analyzed the data and wrote the manuscript. TB participated in the discussion of the results. YB conceived and designed the project, performed the experiments, analyzed the data, and wrote the manuscript. All authors contributed to revising the manuscript and approved the final version.

\section{FUNDING}

This work was supported by the German Research Foundation (CNMPB) to YB. This study was also supported by the Jacob-Henle-Program for Experimental Medicine of the University Medicine Göttingen to JW and ML. MS was supported by Helios Kliniken GmbH. This work was supported in part by the Deutsche Forschungsgemeinschaft (DFG) for PET/MRI use (INST 335/454-1FUGG).

\section{ACKNOWLEDGMENTS}

We acknowledge the support by the Open Access Publication Funds of the Göttingen University.

neuron loss in two mouse models for Alzheimer's disease by deep sequencing. Front. Aging Neurosci. 6:75. doi: 10.3389/fnagi.2014.00075

Boyle, P. A., Buchman, A. S., Wilson, R. S., Leurgans, S. E., and Bennett, D. A. (2009). Association of muscle strength with the risk of Alzheimer disease and the rate of cognitive decline in community-dwelling older persons. Arch. Neurol. 66, 1339-1344. doi: 10.1001/archneurol.2009.240

Brooks, S. P., and Dunnett, S. B. (2009). Tests to assess motor phenotype in mice: a user's guide. Nat. Rev. Neurosci. 10, 519-529. doi: 10.1038/nrn2652

Brooks, S. P., Trueman, R. C., and Dunnett, S. B. (2012). Assessment of motor coordination and balance in mice using the rotarod, elevated bridge, and footprint tests. Curr. Protoc. Mouse Biol. 2, 37-53. doi: 10.1002/9780470942390. mo110165

Brown, R. E., and Wong, A. A. (2007). The influence of visual ability on learning and memory performance in 13 strains of mice. Learn. Mem. 14, 134-144. doi: $10.1101 / \mathrm{lm} .473907$

Buchman, A. S., and Bennett, D. A. (2011). Loss of motor function in preclinical Alzheimer's disease. Expert Rev. Neurother. 11, 665-676. doi: 10.1586/ern.11.57

Buitrago, M. M., Schulz, J. B., Dichgans, J., and Luft, A. R. (2004). Short and long-term motor skill learning in an accelerated rotarod training paradigm. Neurobiol. Learn. Mem. 81, 211-216. doi: 10.1016/j.nlm.2004.01.001

Camicioli, R., Bouchard, T., and Licis, L. (2006). Dual-tasks and walking fast: relationship to extra-pyramidal signs in advanced Alzheimer disease. J. Neurol. Sci. 248, 205-209. doi: 10.1016/j.jns.2006.05.013

Chang, W. -H., Chen, M. C., and Cheng, I. H. (2015). Antroquinonol lowers brain amyloid- $\beta$ levels and improves spatial learning and memory in a transgenic mouse model of Alzheimer's disease. Sci. Rep. 5:15067. doi: 10.1038/srep15067

Chu, T. H., Cummins, K., Sparling, J. S., Tsutsui, S., Brideau, C.,. Nilsson, J. T., Joseph, K. P. R., and Stys, P. K. (2017). Axonal and myelinic pathology in 5xFAD Alzheimer's mouse spinal cord. PLoS One 12:e0188218. doi: 10.1371/journal. pone. 0188218

Cova, I., Clerici, F., Rossi, A., Cucumo, V., Ghiretti, R., Maggiore, L., et al. (2016). Weight loss predicts progression of mild cognitive impairment to Alzheimer's disease. PLoS One 11:e0151710. doi: 10.1371/journal.pone.0151710

Crawley, J., and Bailey, K. (2008). "Anxiety-related behaviors in mice," in Methods of Behavior Analysis in Neuroscience, 2nd Edn, ed. J. Buccafusco (Boca Raton, FL: CRC Press), 77-101. 
Dai, H., Krost, M., and Carey, R. J. (1995). A new methodological approach to the study of habituation: the use of positive and negative behavioral indices of habituation. J. Neurosci. Methods 62, 169-174. doi: 10.1016/0165-0270(95) 00073-9

Deacon, R. M. J. (2013). Measuring motor coordination in mice. J. Vis. Exp. 75:e2609. doi: 10.3791/2609

Deleye, S., Waldron, A.-M., Richardson, J. C., Schmidt, M., Langlois, X., Stroobants, S., et al. (2016). The effects of physiological and methodological determinants on 18F-FDG mouse brain imaging exemplified in a double transgenic Alzheimer model. Mol. Imaging 15:1536012115624919. doi: 10.1177/ 1536012115624919

de Paula, J. J., Albuquerque, M. R., Lage, G. M., Bicalho, M. A., Romano-Silva, M. A., and Malloy-Diniz, L. F. (2016). Impairment of fine motor dexterity in mild cognitive impairment and Alzheimer's disease dementia: association with activities of daily living. Braz. J. Psychiatry 38, 235-238. doi: 10.1590/15164446-2015-1874

Dietrich, K., Bouter, Y., Wittnam, J., Pillot, T., Papot-Couturier, S., Lefebvre, T., et al. (2013). Tg4-42: a new mouse model of Alzheimer's disease-N-truncated beta-amyloid 4-42 affects memory decline and synaptic plasticity. Alzheimers Dement. 9:P498. doi: 10.1016/j.jalz.2013.05.1030

Dineley, K. T., Xia, X., Bui, D., Sweatt, J. D., and Zheng, H. (2002). Accelerated plaque accumulation, associative learning deficits, and up-regulation of alpha 7 nicotinic receptor protein in transgenic mice co-expressing mutant human presenilin 1 and amyloid precursor proteins. J. Biol. Chem. 277, 22768-22780. doi: 10.1074/jbc.M200164200

Ewers, M., Morgan, D. G., Gordon, M. N., and Woodruff-Pak, D. S. (2006). Associative and motor learning in 12-month-old transgenic APP + PS1 mice. Neurobiol. Aging 27, 1118-1128. doi: 10.1016/j.neurobiolaging.2005.05.019

Filali, M., Lalonde, R., Theriault, P., Julien, C., Calon, F., and Planel, E. (2012). Cognitive and non-cognitive behaviors in the triple transgenic mouse model of Alzheimer's disease expressing mutated APP, PS1, and Mapt (3xTg-AD). Behav. Brain Res. 234, 334-342. doi: 10.1016/j.bbr.2012.07.004

Flood, D. G., Reaume, A. G., Dorfman, K. S., Lin, Y. G., Lang, D. M., Trusko, S. P., et al. (2002). FAD mutant PS-1 gene-targeted mice: increased A beta 42 and A beta deposition without APP overproduction. Neurobiol. Aging 23, 335-348.

Garvock-de Montbrun, T., Fertan, E., Stover, K., and Brown, R. E. (2019). Motor deficits in 16-month-old male and female 3xTg-AD mice. Behav. Brain Res. 356, 305-313. doi: 10.1016/j.bbr.2018.09.006

Gillette-Guyonnet, S., Nourhashemi, F., Andrieu, S., Glisezinski, I. de, Ousset, P. J., Riviere, D., et al. (2000). Weight loss in Alzheimer disease. Am. J. Clin. Nutr. 71, 637-642.

Griñán-Ferré, C., Sarroca, S., Ivanova, A., Puigoriol-Illamola, D., Aguado, F., Camins, A., et al. (2016). Epigenetic mechanisms underlying cognitive impairment and Alzheimer disease hallmarks in 5XFAD mice. Aging 8, 664-684. doi: 10.18632/aging.100906

Guérin, O., Andrieu, S., Schneider, S. M., Milano, M., Boulahssass, R., Brocker, P., et al. (2005). Different modes of weight loss in Alzheimer disease: a prospective study of 395 patients. Am. J. Clin. Nutr. 82, 435-441.

Gulinello, M., Gertner, M., Mendoza, G., Schoenfeld, B. P., Oddo, S., LaFerla, F., et al. (2009). Validation of a 2-day water maze protocol in mice. Behav. Brain Res. 196, 220-227. doi: 10.1016/j.bbr.2008.09.002

Hamm, R. J., Pike, B. R., O’Dell, D. M., Lyeth, B. G., and Jenkins, L. W. (1994). The rotarod test: an evaluation of its effectiveness in assessing motor deficits following traumatic brain injury. J. Neurotrauma 11, 187-196. doi: 10.1089/neu. 1994.11.187

Hardy, J. A., and Higgins, G. A. (1992). Alzheimer's disease: the amyloid cascade hypothesis. Science 256, 184-185.

Harris, J. A., Devidze, N., Halabisky, B., Lo, I., Thwin, M. T., Yu, G.-Q., et al. (2010). Many neuronal and behavioral impairments in transgenic mouse models of Alzheimer's disease are independent of caspase cleavage of the amyloid precursor protein. J. Neurosci. 30, 372-381. doi: 10.1523/JNEUROSCI.5341-09. 2010

Hau, J., and Schapiro, S. J. (2002). Handbook of Laboratory Animal Science, Essential Principles and Practices, 2nd Edn. Milton Park: Taylor \& Francis.

Holcomb, L. A., Gordon, M. N., Jantzen, P., Hsiao, K., Duff, K., Morgan, D., et al. (1999). Behavioral changes in transgenic mice expressing both amyloid precursor protein and presenilin-1 mutations: lack of association with amyloid deposits. Behav. Genet. 29, 177-185.

Hsiao, K., Chapman, P., Nilsen, S., Eckman, C., Harigaya, Y., Younkin, S., et al. (1996). Correlative memory deficits, a elevation, and amyloid plaques in transgenic mice. Science 274, 99-103. doi: 10.1126/science.274.5284.99

Hullmann, M., Albrecht, C., van Berlo, D., Gerlofs-Nijland, M. E., Wahle, T., Boots, A. W., et al. (2017). Diesel engine exhaust accelerates plaque formation in a mouse model of Alzheimer's disease. Part. Fibre Toxicol. 14:35. doi: 10.1186/ s12989-017-0213-5

Jacobs, H. I. L., Hopkins, D. A., Mayrhofer, H. C., Bruner, E., van Leeuwen, F. W., Raaijmakers, W., et al. (2018). The cerebellum in Alzheimer's disease: evaluating its role in cognitive decline. Brain 141, 37-47. doi: 10.1093/brain/aw x194

Jankowsky, J. L., Slunt, H. H., Ratovitski, T., Jenkins, N. A., Copeland, N. G., and Borchelt, D. R. (2001). Co-expression of multiple transgenes in mouse CNS: a comparison of strategies. Biomol. Eng. 17, 157-165.

Jawhar, S., Trawicka, A., Jenneckens, C., Bayer, T. A., and Wirths, O. (2012). Motor deficits, neuron loss, and reduced anxiety coinciding with axonal degeneration and intraneuronal $\mathrm{A} \beta$ aggregation in the 5XFAD mouse model of Alzheimer's disease. Neurobiol. Aging 33, 196.e29-196.e40. doi: 10.1016/j.neurobiolaging. 2010.05.027

King, D. L., and Arendash, G. W. (2002). Behavioral characterization of the Tg2576 transgenic model of Alzheimer's disease through 19 months. Physiol. Behav. 75, 627-642. doi: 10.1016/S0031-9384(02)00639-X

Kobayashi, D. T., and Chen, K. S. (2005). Behavioral phenotypes of amyloid-based genetically modified mouse models of Alzheimer's disease. Genes Brain Behav. 4, 173-196. doi: 10.1111/j.1601-183X.2005.00124.x

Kuwabara, Y., Ishizeki, M., Watamura, N., Toba, J., Yoshii, A., Inoue, T., et al. (2014). Impairments of long-term depression induction and motor coordination precede $A \beta$ accumulation in the cerebellum of APPswe/PS1dE9 double transgenic mice. J. Neurochem. 130, 432-443. doi: 10.1111/jnc.12728

Lalonde, R., Dumont, M., Staufenbiel, M., and Strazielle, C. (2005a). Neurobehavioral characterization of APP23 transgenic mice with the SHIRPA primary screen. Behav. Brain Res. 157, 91-98. doi: 10.1016/j.bbr.2004. 06.020

Lalonde, R., Kim, H. D., Maxwell, J. A., and Fukuchi, K. (2005b). Exploratory activity and spatial learning in 12-month-old APP(695)SWE/co+PS1/DeltaE9 mice with amyloid plaques. Neurosci. Lett. 390, 87-92. doi: 10.1016/j.neulet. 2005.08.028

Lalonde, R., Fukuchi, K.-I., and Strazielle, C. (2012). Neurologic and motor dysfunctions in APP transgenic mice. Rev. Neurosci. 23, 363-379. doi: 10.1515/ revneuro-2012-0041

Lalonde, R., Kim, H. D., and Fukuchi, K. (2004). Exploratory activity, anxiety, and motor coordination in bigenic APPswe + PS1/DeltaE9 mice. Neurosci. Lett. 369, 156-161. doi: 10.1016/j.neulet.2004.07.069

Larson, E. B., Kukull, W. A., and Katzman, R. L. (1992). Cognitive impairment: dementia and Alzheimer's disease. Annu. Rev. Public Health 13, 431-449. doi: 10.1146/annurev.pu.13.050192.002243

Larson, B., Wang, L., Bowen, J. D., McCormick, W. C., Teri, L., Crane, P., et al. (2006). Exercise is associated with reduced risk for incident dementia among persons 65 years of age and older. J. Cardiopulm. Rehabil. 26, 244-245. doi: 10.1097/00008483-200607000-00008

Le Marec, N., and Lalonde, R. (1997). Sensorimotor learning and retention during equilibrium tests in Purkinje cell degeneration mutant mice. Brain Res. 768, 310-316. doi: 10.1016/S0006-8993(97)00666-5

Lee, H.-G., Casadesus, G., Perry, G., Bryan, K., and Smith, M. (2009). “Transgenic mouse models of Alzheimer's disease," in Methods of Behavior analysis in Neuroscience, ed. J. J. Buccafusco (Boca Raton, FL: CRC Press), 1-18.

Lopez, O. L., Wisnieski, S. R., Becker, J. T., Boiler, F., and DeKosky, S. T. (1997). Extrapyramidal signs in patients with probable Alzheimer disease. Arch. Neurol. 54, 969-975. doi: 10.1001/archneur.1997.005502000 33007

Lopez-Noguerola, J. S., Giessen, N. M. E., Ueberück, M., Meißner, J. N., Pelgrim, C. E., Adams, J., et al. (2018). Synergistic effect on neurodegeneration by N-truncated $A \beta 4-42$ and pyroglutamate $A \beta 3-42$ in a mouse model of Alzheimer's disease. Front. Aging Neurosci. 10:64. doi: 10.3389/fnagi.2018. 00064 
Luong, T. N., Carlisle, H. J., Southwell, A., and Patterson, P. H. (2011). Assessment of motor balance and coordination in mice using the balance beam. J. Vis. Exp. 49:2376. doi: 10.3791/2376

Macdonald, I. R., DeBay, D. R., Reid, G. A., O'Leary, T. P., Jollymore, C. T., Mawko, G., et al. (2014). Early detection of cerebral glucose uptake changes in the 5XFAD mouse. Curr. Alzheimer Res. 11, 450-460. doi: 10.2174/ 1567205011666140505111354

Masters, C. L., Simms, G., Weinman, N. A., Multhaup, G., McDonald, B. L., and Beyreuther, K. (1985). Amyloid plaque core protein in Alzheimer disease and Down syndrome. Proc. Natl. Acad. Sci. U.S.A. 82, 4245-4249.

Meissner, J. N., Bouter, Y., and Bayer, T. A. (2014). Neuron loss and behavioral deficits in the TBA42 mouse model expressing N-truncated pyroglutamate amyloid-beta3-42. J. Alzheimers Dis. 45, 471-482. doi: 10.3233/JAD- 142868

Miller, B. R., Dorner, J. L., Shou, M., Sari, Y., Barton, S. J., Sengelaub, D. R., et al. (2008). Up-regulation of GLT1 expression increases glutamate uptake and attenuates the Huntington's disease phenotype in the R6/2 mouse. Neuroscience 153, 329-337. doi: 10.1016/j.neuroscience.2008.02.004

Moran, P. M., Higgins, L. S., Cordell, B., and Moser, P. C. (1995). Age-related learning deficits in transgenic mice expressing the 751-amino acid isoform of human beta-amyloid precursor protein. Proc. Natl. Acad. Sci. U.S.A. 92, 5341-5345.

Morton, S. M., and Bastian, A. J. (2004). Cerebellar control of balance and locomotion. Neuroscientist 10, 247-259. doi: 10.1177/1073858404263517

Mucke, L., Masliah, E., Yu, G. -Q., Mallory, M., Rockenstein, E. M., Tatsuno, G., et al. (2000). High-level neuronal expression of $A \beta$ 1-42 in wild-type human amyloid protein precursor transgenic mice: synaptotoxicity without plaque formation. J. Neurosci. 20, 4050-4058. doi: 10.1523/JNEUROSCI.20-11-04050. 2000

Oakley, H., Cole, S. L., Logan, S., Maus, E., Shao, P., Craft, J., et al. (2006). Intraneuronal beta-amyloid aggregates, neurodegeneration, and neuron loss in transgenic mice with five familial Alzheimer's disease mutations: potential factors in amyloid plaque formation. J. Neurosci. 26, 10129-10140. doi: 10.1523/ JNEUROSCI.1202-06.2006

Oddo, S., Caccamo, A., Shepherd, J. D., Murphy, M. P., Golde, T. E., Kayed, R., et al. (2003). Triple-transgenic model of Alzheimer's disease with plaques and tangles: intracellular Abeta and synaptic dysfunction. Neuron 39, 409-421.

O'Keeffe, S. T., Kazeem, H., Philpott, R. M., Playfer, J. R., Gosney, M., and Lye, M. (1996). Gait disturbance in Alzheimer's disease: a clinical study. Age Ageing 25, 313-316.

O’Leary, T. P., Mantolino, H. M., Stover, K. R., and Brown, R. E. (2018a). Agerelated deterioration of motor function in male and female 5xFAD mice from 3 to 16 months of age. Genes Brain Behav. doi: 10.1111/gbb.12538

O'Leary, T. P., Robertson, A., Chipman, P. H., Rafuse, V. F., and Brown, R. E. (2018b). Motor function deficits in the 12 month-old female 5xFAD mouse model of Alzheimer's disease. Behav. Brain Res. 337, 256-263. doi: 10.1016/j. bbr.2017.09.009

Oore, J. J., Fraser, L. M., and Brown, R. E. (2013). Age-related changes in motor ability and motor learning in triple transgenic (3xTg-AD) and control (B6129SF1/J) mice on the accelerating rotarod. Proc. N. S. Inst. Sci. 47, 281-296. doi: $10.15273 /$ pnsis.v47i2.4343

Perucho, J., Casarejos, M. J., Rubio, I., Rodriguez-Navarro, J. A., Gómez, A., Ampuero, I., et al. (2010). The effects of parkin suppression on the behaviour, amyloid processing, and cell survival in APP mutant transgenic mice. Exp. Neurol. 221, 54-67. doi: 10.1016/j.expneurol.2009. 09.029

Pettersson, A. F., Engardt, M., and Wahlund, L. -O. (2002). Activity level and balance in subjects with mild Alzheimer's disease. Dement. Geriatr. Cogn. Disord. 13, 213-216. doi: 10.1159/000057699

Pike, C. J., Overman, M. J., and Cotman, C. W. (1995). Amino-terminal deletions enhance aggregation of beta-amyloid peptides in vitro. J. Biol. Chem. 270, 23895-23898.

Platt, B., Drever, B., Koss, D., Stoppelkamp, S., Jyoti, A., Plano, A., et al. (2011). Abnormal cognition, sleep, EEG and brain metabolism in a novel knockin Alzheimer mouse, PLB1. PLoS One 6:e27068. doi: 10.1371/journal.pone. 0027068

Porras-García, M. E., Ruiz, R., Pérez-Villegas, E. M., and Armengol, J. Á. (2013). Motor learning of mice lacking cerebellar Purkinje cells. Front. Neuroanatomy 7:4. doi: 10.3389/fnana.2013.00004
Portelius, E., Bogdanovic, N., Gustavsson, M. K., Volkmann, I., Brinkmalm, G., Zetterberg, H., et al. (2010). Mass spectrometric characterization of brain amyloid beta isoform signatures in familial and sporadic Alzheimer's disease. Acta Neuropathol. 120, 185-193. doi: 10.1007/s00401-0100690-1

Probst, A., Gotz, J., Wiederhold, K. H., Tolnay, M., Mistl, C., Jaton, A. L., et al. (2000). Axonopathy and amyotrophy in mice transgenic for human four-repeat tau protein. Acta Neuropathol. 99, 469-481.

Pugh, P. L., Richardson, J. C., Bate, S. T., Upton, N., and Sunter, D. (2007). Non-cognitive behaviours in an APP/PS1 transgenic model of Alzheimer's disease. Behav. Brain Res. 178, 18-28. doi: 10.1016/j.bbr.2006. 11.044

Sadowski, M., Pankiewicz, J., Scholtzova, H., Ji, Y., Quartermain, D., Jensen, C. H., et al. (2004). Amyloid- $\beta$ deposition is associated with decreased hippocampal glucose metabolism and spatial memory impairment in APP/PS1 mice. J. Neuropathol. Exp. Neurol. 63, 418-428. doi: 10.1093/jnen/63. 5.418

Sawmiller, D., Li, S., Mori, T., Habib, A., Rongo, D., Delic, V., et al. (2017). Beneficial effects of a pyrroloquinolinequinone-containing dietary formulation on motor deficiency, cognitive decline and mitochondrial dysfunction in a mouse model of Alzheimer's disease. Heliyon 3:e00279. doi: 10.1016/j.heliyon. 2017.e00279

Scarmeas, N., Hadjigeorgiou, G. M., Papadimitriou, A., Dubois, B., Sarazin, M., Brandt, J., et al. (2004). Motor signs during the course of Alzheimer disease. Neurology 63, 975-982. doi: 10.1212/01.WNL.0000138440.399 $18.0 \mathrm{C}$

Scattoni, M. L., Gasparini, L., Alleva, E., Goedert, M., Calamandrei, G., and Spillantini, M. G. (2010). Early behavioural markers of disease in P301S tau transgenic mice. Behav. Brain Res. 208, 250-257. doi: 10.1016/j.bbr.2009. 12.002

Schneider, F., Baldauf, K., Wetzel, W., and Reymann, K. G. (2014). Behavioral and EEG changes in male 5xFAD mice. Physiol. Behav. 135, 25-33. doi: 10.1016/j. physbeh.2014.05.041

Seibenhener, M. L., and Wooten, M. C. (2015). Use of the Open Field Maze to measure locomotor and anxiety-like behavior in mice. J. Vis. Exp. 96:e52434. doi: $10.3791 / 52434$

Shiotsuki, H., Yoshimi, K., Shimo, Y., Funayama, M., Takamatsu, Y., Ikeda, K., et al. (2010). A rotarod test for evaluation of motor skill learning. J. Neurosci. Methods 189, 180-185. doi: 10.1016/j.jneumeth.2010.03.026

Shukla, V., Zheng, Y.-L., Mishra, S. K., Amin, N. D., Steiner, J., Grant, P., et al. (2013). A truncated peptide from p35, a Cdk5 activator, prevents Alzheimer's disease phenotypes in model mice. FASEB J. 27, 174-186. doi: 10.1096/fj.12217497

Singh, B. K., Vatsa, N., Kumar, V., Shekhar, S., Sharma, A., and Jana, N. R. (2017). Ube3a deficiency inhibits amyloid plaque formation in APPswe/PS1 $\delta$ E9 mouse model of Alzheimer's disease. Hum. Mol. Genet. 26, 4042-4054. doi: 10.1093/ hmg/ddx295

Stevens, L. M., and Brown, R. E. (2015). Reference and working memory deficits in the 3xTg-AD mouse between 2 and 15-months of age: a crosssectional study. Behav. Brain Res. 278, 496-505. doi: 10.1016/j.bbr.2014. 10.033

Stover, K. R., Campbell, M. A., van Winssen, C. M., and Brown, R. E. (2015). Analysis of motor function in 6-month-old male and female 3xTg-AD mice. Behav. Brain Res. 281, 16-23. doi: 10.1016/j.bbr.2014.11.046

Sturchler-Pierrat, C., Abramowski, D., Duke, M., Wiederhold, K. H., Mistl, C., Rothacher, S., et al. (1997). Two amyloid precursor protein transgenic mouse models with Alzheimer disease-like pathology. Proc. Natl. Acad. Sci. U.S.A. 94, 13287-13292.

Takkinen, J. S., López-Picón, F. R., Al Majidi, R., Eskola, O., Krzyczmonik, A., Keller, T., et al. (2017). Brain energy metabolism and neuroinflammation in ageing APP/PS1-21 mice using longitudinal 18F-FDG and 18F-DPA-714 PET imaging. J. Cereb. Blood Flow Metab. 37, 2870-2882. doi: 10.1177/ 0271678X16677990

Tesseur, I., van Dorpe, J., Bruynseels, K., Bronfman, F., Sciot, R., van Lommel, A., et al. (2000). Prominent axonopathy and disruption of axonal transport in transgenic mice expressing human apolipoprotein E4 in neurons of brain and spinal cord. Am. J. Pathol. 157, 1495-1510. doi: 10.1016/S0002-9440(10)64 $788-8$ 
van Dam, D., D’Hooge, R., Staufenbiel, M., van Ginneken, C., van Meir, F., and de Deyn, P. P. (2003). Age-dependent cognitive decline in the APP23 model precedes amyloid deposition. Eur. J. Neurosci. 17, 388-396. doi: 10.1046/j.14609568.2003.02444.x

Waite, L. M., Grayson, D. A., Piguet, O., Creasey, H., Bennett, H. P., and Broe, G. A. (2005). Gait slowing as a predictor of incident dementia: 6-year longitudinal data from the Sydney Older Persons Study. J. Neurol. Sci. 229-230, 89-93. doi: 10.1016/j.jns.2004.11.009

Waldron, A.-M., Wyffels, L., Verhaeghe, J., Richardson, J. C., Schmidt, M., Stroobants, S., et al. (2017). Longitudinal characterization of 18F-FDG and 18FAV45 uptake in the double transgenic TASTPM mouse model. J. Alzheimers Dis. 55, 1537-1548. doi: 10.3233/JAD-160760

Walsh, R. N., and Cummins, R. A. (1976). The open-field test: a critical review. Psychol. Bull. 83, 482-504.

Webster, S. J., Bachstetter, A. D., and van Eldik, L. J. (2013). Comprehensive behavioral characterization of an APP/PS-1 double knock-in mouse model of Alzheimer's disease. Alzheimers Res. Ther. 5:28. doi: 10.1186/alzrt182

White, H., Pieper, C., and Schmader, K. (1998). The association of weight change in Alzheimer's disease with severity of disease and mortality: a longitudinal analysis. J. Am. Geriatr. Soc. 46, 1223-1227.

Wilson, R. S., Bennett, D. A., Gilley, D. W., Beckett, L. A., Schneider, J. A., and Evans, D. A. (2000). Progression of parkinsonism and loss of cognitive function in Alzheimer disease. Arch. Neurol. 57, 855-860. doi: 10.1001/archneur.57.6.855

Wirths, O., and Bayer, T. A. (2008). Motor impairment in Alzheimer's disease and transgenic Alzheimer's disease mouse models. Genes Brain Behav. 7(Suppl. 1), 1-5. doi: 10.1111/j.1601-183X.2007.00373.x

Wirths, O., Breyhan, H., Schäfer, S., Roth, C., and Bayer, T. A. (2008). Deficits in working memory and motor performance in the APP/PS1ki mouse model for Alzheimer's disease. Neurobiol. Aging 29, 891-901. doi: 10.1016/j. neurobiolaging.2006.12.004

Wirths, O., Weis, J., Kayed, R., Saido, T. C., and Bayer, T. A. (2007). Agedependent axonal degeneration in an Alzheimer mouse model. Neurobiol. Aging 28, 1689-1699. doi: 10.1016/j.neurobiolaging.2006.07.021
Wittnam, J. L., Portelius, E., Zetterberg, H., Gustavsson, M. K., Schilling, S., Koch, B., et al. (2012). Pyroglutamate amyloid $\beta(A \beta)$ aggravates behavioral deficits in transgenic amyloid mouse model for Alzheimer disease. J. Biol. Chem. 287, 8154-8162. doi: 10.1074/jbc.M111.308601

Xu, J., Sato, S., Okuyama, S., Swan, R. J., Jacobsen, M. T., Strunk, E., et al. (2010). Tau-tubulin kinase 1 enhances prefibrillar tau aggregation and motor neuron degeneration in P301L FTDP-17 tau-mutant mice. FASEB J. 24, 2904-2915. doi: 10.1096/fj.09-15 0144

Yan, J. H., and Zhou, C. L. (2009). Effects of motor practice on cognitive disorders in older adults. Eur. Rev. Aging Phys. Act. 6, 67-74. doi: 10.1007/s11556-0090049-6

Zidan, M., Arcoverde, C., Araújo, N. B. D., Vasques, P., Rios, A., Laks, J., et al. (2012). Alterações motoras e funcionais em diferentes estágios da doença de Alzheimer. Rev. Psiquiatr. Clín. 39, 161-165. doi: 10.1590/S010160832012000500003

Conflict of Interest Statement: University Medicine Göttingen has been granted a patent on the Tg4-42 mouse model, on which TB is listed as an inventor.

The remaining authors declare that the research was conducted in the absence of any commercial or financial relationships that could be construed as a potential conflict of interest.

The reviewer SV declared a past collaboration with one of the authors TB to the handling Editor.

Copyright (C) 2019 Wagner, Sichler, Schleicher, Franke, Irwin, Löw, Beindorff, Bouter, Bayer and Bouter. This is an open-access article distributed under the terms of the Creative Commons Attribution License (CC BY). The use, distribution or reproduction in other forums is permitted, provided the original author(s) and the copyright owner(s) are credited and that the original publication in this journal is cited, in accordance with accepted academic practice. No use, distribution or reproduction is permitted which does not comply with these terms. 